\title{
Predictive abilities of cardiovascular biomarkers to rapid decline of renal function in Chinese community-dwelling population: a 5-year prospective analysis
}

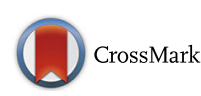

Shihui $\mathrm{Fu}^{1,2+}$, Chunling Liu ${ }^{3+}$, Leiming Luo ${ }^{1 *}$ and Ping $\mathrm{Ye}^{1 *}$

\begin{abstract}
Background: Predictive abilities of cardiovascular biomarkers to renal function decline are more significant in Chinese community-dwelling population without glomerular filtration rate (GFR) below $60 \mathrm{ml} / \mathrm{min} / 1.73 \mathrm{~m}^{2}$, and long-term prospective study is an optimal choice to explore this problem. Aim of this analysis was to observe this problem during the follow-up of 5 years.
\end{abstract}

Methods: In a large medical check-up program in Beijing, there were 948 participants with renal function evaluated at baseline and follow-up of 5 years. Physical examinations were performed by well-trained physicians. Blood samples were analyzed by qualified technicians in central laboratory.

Results: Median rate of renal function decline was $1.46(0.42-2.91) \mathrm{mL} / \mathrm{min} / 1.73 \mathrm{~m}^{2} /$ year. Rapid decline of renal function had a prevalence of 23.5\% (223 participants). Multivariate linear and Logistic regression analyses confirmed that age, sex, baseline GFR, homocysteine and N-terminal pro B-type natriuretic peptide (NT-proBNP) had independently predictive abilities to renal function decline rate and rapid decline of renal function ( $p<0.05$ for all). High-sensitivity cardiac troponin T (hs-cTnT), carotid femoral pulse wave velocity and central augmentation index had no statistically independent association with renal function decline rate and rapid decline of renal function ( $p>0.05$ for all).

Conclusions: Homocysteine and NT-proBNP rather than hs-cTnT had independently predictive abilities to rapid decline of renal function in Chinese community-dwelling population without GFR below $60 \mathrm{ml} / \mathrm{min} / 1.73 \mathrm{~m}^{2}$. Baseline GFR was an independent factor predicting the rapid decline of renal function. Arterial stiffness and compliance had no independent effect on rapid decline of renal function. This analysis has a significant implication for public health, and changing the homocysteine and NT-proBNP levels might slow the rapid decline of renal function.

Keywords: Arterial stiffness and compliance, Cardiovascular biomarkers, Chinese community-dwelling population, Glomerular filtration rate, Rapid decline of renal function

\section{Background}

During the last few decades, rapid decline of renal function continues to grow in prevalence, and this trend is particularly obvious in patients with cardiovascular disease (CVD) [1]. Patients with CVD have clearly higher morbidity and mortality of chronic kidney disease

\footnotetext{
* Correspondence: Ileim@sina.com; sci301@126.com

${ }^{\dagger}$ Equal contributors

'Department of Geriatric Cardiology, Chinese People's Liberation Army

General Hospital, Beijing, China

Full list of author information is available at the end of the article
}

(CKD) compared with those without CVD [2,3]. As the established cardiovascular biomarkers, homocysteine, $\mathrm{N}$ terminal pro B-type natriuretic peptide (NT-proBNP) and high-sensitivity cardiac troponin $\mathrm{T}$ (hs-cTnT) are considered to be elevated in patients with rapid decline of renal function, especially those with end stage renal disease (ESRD) [4, 5]. Previous studies have observed the relationships between cardiovascular biomarkers and renal function decline in patients with glomerular filtration rate (GFR) below $60 \mathrm{ml} / \mathrm{min} / 1.73 \mathrm{~m}^{2}$, and yielded the controversial results $[6-8]$. However, predictive 
abilities of cardiovascular biomarkers to renal function decline are more significant in community-dwelling population without GFR below $60 \mathrm{ml} / \mathrm{min} / 1.73 \mathrm{~m}^{2}$, and it is essential to analyze this problem in this population. Moreover, these cardiovascular biomarkers might play an etiologic role in renal function decline, and analyzing their relationships could promote the development of preventive strategies to slow the rapid decline of renal function.

Predictive abilities can not be fully evaluated by crosssectional and short-term studies, and long-term prospective study is an optimal choice to explore the predictive abilities of cardiovascular biomarkers to renal function decline [9]. Moreover, this problem differs between racial groups, and there are few studies about this problem in China [10]. Therefore, aim of this prospective analysis was to observe the predictive abilities of cardiovascular biomarkers to renal function decline during the follow-up of 5 years in Chinese community-dwelling population without GFR below $60 \mathrm{ml} / \mathrm{min} / 1.73 \mathrm{~m}^{2}$.

\section{Methods}

\section{Study population}

This prospective analysis was performed in 1680 participants at least 18 years of age through a medical examination in Beijing, China. Participants were enrolled between May 2007 and July 2009, and the follow-up visit was conducted between February 2013 and September 2013. After 181 participants were lost, 1499 participants were followed up for 5 years. Exclusion criteria were death (52 participants), GFR below $60 \mathrm{ml} / \mathrm{min} / 1.73 \mathrm{~m}^{2}$ (12 participants) and missing values for variables (487 participants). The final study population was comprised of 948 participants.

\section{Physical examination}

Physical examination was conducted by well-trained physicians. Resting blood pressure (BP) was determined by taking the mean of two measurements from the right arm of participants in the seated position with a standard mercury sphygmomanometer (Yuwell Medical Equipment \& Supply Co., Ltd., Jiangsu, China). Hypertension was defined as mean systolic blood pressure (SBP) $\geq 140 \mathrm{mmHg}$, mean diastolic blood pressure (DBP) $\geq 90 \mathrm{mmHg}$, and/or use of any anti-hypertensive medications.

\section{Biochemical evaluation}

Fasting blood samples were collected between 8 a.m. and 10 a.m., and sent to our central laboratory. Cardiovascular biomarkers were evaluated according to standard methods described by the manufacturers. Concentrations of fasting blood glucose (FBG), triglyceride (TG), high-density lipoprotein cholesterol (HDL-c) and low-density lipoprotein cholesterol (LDL-c) were quantified with Roche enzymatic assays (Roche Products Ltd., Basel, Switzerland) on a Roche autoanalyzer (Roche Products Ltd., Basel, Switzerland). Oral glucose tolerance test was done at timed intervals of two hours after drinking $75 \mathrm{~g}$ glucose load. Diabetes was defined as $F B G \geq 7.0 \mathrm{mmol} / \mathrm{L}$, postprandial blood glucose $(\mathrm{PBG}) \geq 11.1 \mathrm{mmol} / \mathrm{L}$, and/or use of oral hypoglycemic medications or insulin. Concentrations of NT-proBNP were measured with electrochemiluminescence immunoassay (Roche Diagnostics $\mathrm{GmbH}$ ) on an autoanalyzer (COBAS 6000; Roche Products Ltd., Basel, Switzerland). Concentrations of homocysteine were measured by high-performance chromatography with fluorometric detection. Concentrations of hs-cTnT were measured with Elecsys Troponin $\mathrm{T}$ high sensitive assay (Roche Products Ltd., Basel, Switzerland) by electrochemiluminescence immunoassay on a Modular Analytics E170 autoanalyzer (Roche Products Ltd., Basel, Switzerland). All assays were performed by qualified technicians without knowledge of clinical data.

\section{Arterial stiffness and compliance assessment}

Central arterial stiffness was assessed by automated measurement of carotid femoral pulse wave velocity (cfPWV; Créatech, Besançon, France). cfPWV (m/s) was measured with two strain-gauge transducers (TY-306 Fukuda pressure-sensitive transducer; Fukuda Denshi Co., Tokyo, Japan) fixed transcutaneously over the carotid and femoral arteries (all on the right side), and then calculated from pulse transit time and distance between two recording sites [distance (m)/time (s)]. Central arterial compliance was assessed by automated measurement of central augmentation index (cAIx; SphygmoCor, Sydney, Australia). Central pressure waveform was obtained using its transfer function after mean radial artery waveform was calculated.

\section{Renal function decline}

GFR was calculated using Chinese modified Modification of Diet in Renal Disease (MDRD) eq. [175 $\times$ plasma creatinine $^{-1.234} \times$ age $^{-0.179} \times 0.79$ (if female)], where plasma creatinine was in $\mathrm{mg} / \mathrm{dL}$ [11]. Concentrations of serum creatinine were measured with enzymatic assay (Roche Diagnostics GmbH) on a Hitachi 7600 autoanalyzer (Hitachi, Tokyo, Japan). Renal function decline rate was the change in GFR per year. Rapid decline of renal function was defined as a loss of GFR more than $3 \mathrm{ml} /$ $\min / 1.73 \mathrm{~m}^{2}$ per year $[12,13]$.

\section{Statistical analysis}

Continuous variables with normal distribution were described as mean (standard deviation) and compared with Student's t-test. Continuous variables with skewed distribution were described as median (interquartile range) and compared with Mann-Whitney U test. Categorical 
variables were described as number (percentage) and compared with $\chi^{2}$ test. Baseline characteristics were compared between participants with and without rapid decline of renal function. Pearson and Spearman correlation analyses were used for simple correlation. Wilcoxon signed-rank test was conducted to compare the GFR levels at baseline and follow-up. Linear and Logistic regression analyses were conducted to observe the predictive abilities of cardiovascular biomarkers to renal function decline rate and rapid decline of renal function, respectively, after adjustment for age, sex, coronary artery disease, hypertension, diabetes, BMI, SBP, DBP, TG, HDL-c, LDL-c, FBG, PBG, baseline GFR, homocysteine, NT-proBNP, hs-cTnT, cfPWV and cAIx. Data were dealt with Statistical Package for Social Sciences (SPSS) version 17.0 (SPSS Inc., Chicago, IL, USA). Statistical significance referred to $p<0.05$.

\section{Results}

All participants had a median age of 60 (range: 25-96) years, and $44.6 \%$ (423 participants) were men (Table 1). Median baseline GFR level was 87.79 (79.27-96.89) mL/ $\min / 1.73 \mathrm{~m}^{2}$, and median follow-up GFR level was 80.10 (72.02-87.89) $\mathrm{mL} / \mathrm{min} / 1.73 \mathrm{~m}^{2}$ ( $p<0.001$ for change). Median rate of renal function decline was $1.46(0.42-$ 2.91) $\mathrm{mL} / \mathrm{min} / 1.73 \mathrm{~m}^{2} /$ year. Median levels of homocysteine and NT-proBNP were 16.75 (13.60-20.70) $\mu \mathrm{mol} / \mathrm{L}$ and 38.41 (18.40-73.54) pg/ml, respectively. Rapid decline of renal function had a prevalence of 23.5\% (223 participants). Age, baseline GFR, homocysteine, NTproBNP and PBG levels, and proportions of men, hypertension and diabetes, were significantly higher in participants with rapid decline of renal function compared with those without rapid decline of renal function $(p<0.05$ for all; Table 1$)$.

Logistic regression analysis confirmed that not only age, sex and baseline GFR levels, but also homocysteine and NT-proBNP levels had independently predictive abilities to renal function decline rate (NT-proBNP: $p=0.001$; others: $p<0.001$ for all; Table 2). Levels of hs-cTnT, cfPWV and cAIx had no statistically independent association with renal function decline rate $(p>0.05$ for all). Linear regression analysis confirmed that not only age, sex, baseline GFR levels and hypertension, but

Table 1 Characteristics of study population with and without rapid decline of renal function

\begin{tabular}{|c|c|c|c|c|}
\hline Characteristics & Total population $(n=948)$ & $\begin{array}{l}\text { With rapid decline of renal function } \\
(n=223)\end{array}$ & $\begin{array}{l}\text { Without rapid decline of renal function } \\
(n=725)\end{array}$ & $P$-value \\
\hline Age (year) & $60(52-69)$ & $61(53-71)$ & $60(52-69)$ & 0.033 \\
\hline Men (\%) & $423(44.6)$ & $80(35.9)$ & $343(47.3)$ & 0.003 \\
\hline BMI $\left(\mathrm{kg} / \mathrm{m}^{2}\right)$ & 25.32(23.37-27.76) & 25.46(23.88-28.13) & 25.27(23.19-27.64) & 0.089 \\
\hline SBP $(\mathrm{mmHg})$ & $129(117-141)$ & 130(119-140) & $128(116-141)$ & 0.701 \\
\hline $\mathrm{DBP}(\mathrm{mmHg})$ & $77(70-84)$ & $79(70-83)$ & $77(70-84)$ & 0.221 \\
\hline CAD (\%) & $107(11.3)$ & $27(12.1)$ & $80(11.0)$ & 0.658 \\
\hline Hypertension (\%) & $471(49.7)$ & $125(56.1)$ & $346(47.7)$ & 0.030 \\
\hline Diabetes (\%) & $246(25.9)$ & $77(34.5)$ & 169(23.3) & 0.001 \\
\hline $\operatorname{cfPWV}(\mathrm{m} / \mathrm{s})$ & $10.7(9.3-12.6)$ & 10.8(9.4-12.8) & 10.6(9.3-12.6) & 0.404 \\
\hline cAlx (\%) & $27(20-33)$ & $28(22-33)$ & $27(20-33)$ & 0.090 \\
\hline TG $(\mathrm{mmol} / \mathrm{L})$ & $1.47(1.08-2.11)$ & $1.49(1.14-2.17)$ & $1.47(1.07-2.10)$ & 0.328 \\
\hline $\mathrm{HDL}-\mathrm{c}(\mathrm{mmol} / \mathrm{L})$ & $1.34(1.13-1.55)$ & $1.31(1.11-1.50)$ & $1.35(1.14-1.59)$ & 0.064 \\
\hline LDL-c (mmol/L) & $2.89(2.42-3.29)$ & $2.91(2.53-3.24)$ & $2.88(2.40-3.31)$ & 0.712 \\
\hline FBG (mmol/L) & $4.97(4.52-5.48)$ & $4.97(4.41-5.66)$ & $4.97(4.54-5.46)$ & 0.893 \\
\hline PBG (mmol/L) & $6.54(5.28-8.46)$ & $6.89(5.52-10.12)$ & $6.40(5.26-8.25)$ & 0.001 \\
\hline Homocysteine $(\mu \mathrm{mol} / \mathrm{L})$ & 16.75(13.60-20.70) & 17.30(14.70-20.90) & 16.30(13.20-20.65) & 0.006 \\
\hline NT-proBNP (pg/ml) & $38.41(18.40-73.54)$ & $41.55(22.50-84.77)$ & $37.30(17.05-70.30)$ & 0.017 \\
\hline $\mathrm{Hs}-\mathrm{cTnT}(\mathrm{pg} / \mathrm{ml})$ & $4.00(3.00-8.19)$ & 4.19(3.00-9.13) & $4.00(3.00-7.92)$ & 0.359 \\
\hline Baseline GFR (mL/min/1.73m²) & 87.79(79.27-96.89) & $102.01(89.94-113.83)$ & 85.19(77.89-92.32) & $<0.001$ \\
\hline Follow-up GFR (mL/min/1.73m²) & $80.10(72.02-87.89)$ & $76.47(67.75-83.84)$ & 81.19(73.27-88.85) & $<0.001$ \\
\hline$\triangle$ GFR/year $\left(\mathrm{mL} / \mathrm{min} / 1.73 \mathrm{~m}^{2} /\right.$ year $)$ & $1.46(0.42-2.91)$ & $4.40(3.45-6.38)$ & $1.01(0.08-1.81)$ & $<0.001$ \\
\hline
\end{tabular}

Abbreviations: BMI: body mass index; cAlx: central augmentation index; CAD: coronary artery disease; cfPWV: carotid-femoral pulse wave velocity; DBP: diastolic blood pressure; FBG: fasting blood glucose; GFR: glomerular filtration rate. HDL-c: high-density lipoprotein cholesterol; hs-cTnT: high-sensitivity cardiac troponin T; LDL-c: low-density lipoprotein cholesterol; NT-proBNP: N-terminal pro B-type natriuretic peptide; PBG: postprandial blood glucose; SBP: systolic blood pressure; TG: triglyceride 
Table 2 Predictive abilities of cardiovascular biomarkers to renal function decline rate in simple correlation and linear regression analyses

\begin{tabular}{|c|c|c|c|c|}
\hline Characteristics & $r$ & $P$-value & $\beta$ & $P$-value \\
\hline Age (year) & 0.057 & 0.078 & 0.180 & $<0.001$ \\
\hline Men (\%) & 0.124 & $<0.001$ & 0.142 & $<0.001$ \\
\hline BMI $\left(\mathrm{kg} / \mathrm{m}^{2}\right)$ & 0.049 & 0.132 & 0.020 & 0.481 \\
\hline $\mathrm{SBP}(\mathrm{mmHg})$ & 0.015 & 0.640 & -0.026 & 0.517 \\
\hline $\mathrm{DBP}(\mathrm{mmHg})$ & -0.001 & 0.973 & 0.009 & 0.799 \\
\hline CAD (\%) & 0.060 & 0.067 & 0.017 & 0.526 \\
\hline Hypertension (\%) & 0.057 & 0.077 & 0.062 & 0.070 \\
\hline Diabetes (\%) & 0.128 & $<0.001$ & -0.008 & 0.821 \\
\hline $\operatorname{cfPWW}(\mathrm{m} / \mathrm{s})$ & -0.002 & 0.939 & -0.023 & 0.476 \\
\hline cAlx (\%) & 0.071 & 0.029 & $<0.001$ & 0.998 \\
\hline TG (mmol/L) & 0.040 & 0.224 & -0.033 & 0.244 \\
\hline $\mathrm{HDL}-\mathrm{c}(\mathrm{mmol} / \mathrm{L})$ & -0.038 & 0.238 & -0.038 & 0.211 \\
\hline LDL-c (mmol/L) & 0.045 & 0.165 & 0.016 & 0.554 \\
\hline FBG (mmol/L) & -0.037 & 0.251 & 0.028 & 0.503 \\
\hline PBG (mmol/L) & 0.109 & 0.001 & 0.052 & 0.271 \\
\hline Homocysteine $(\mu \mathrm{mol} / \mathrm{L})$ & 0.116 & $<0.001$ & 0.158 & $<0.001$ \\
\hline NT-proBNP (pg/ml) & 0.081 & 0.013 & 0.088 & 0.001 \\
\hline Hs-cTnT (pg/ml) & 0.044 & 0.179 & 0.014 & 0.599 \\
\hline Baseline GFR (mL/min/1.73m²) & 0.480 & $<0.001$ & 0.620 & $<0.001$ \\
\hline \multicolumn{5}{|c|}{$\begin{array}{l}\text { Abbreviations: BMI: body mass index; cAlx: central augmentation index; CAD: } \\
\text { coronary artery disease; cfPWV: carotid-femoral pulse wave velocity; DBP: } \\
\text { diastolic blood pressure; FBG: fasting blood glucose; GFR: glomerular filtration } \\
\text { rate; HDL-c: high-density lipoprotein cholesterol; hs-cTnT: high-sensitivity } \\
\text { cardiac troponin T; LDL-c: low-density lipoprotein cholesterol; NT-proBNP: N- } \\
\text { terminal pro B-type natriuretic peptide; PBG: postprandial blood glucose; SBP: } \\
\text { systolic blood pressure; TG: triglyceride }\end{array}$} \\
\hline
\end{tabular}

also homocysteine and NT-proBNP levels had independently predictive abilities to rapid decline of renal function (hypertension: 0.029; NT-proBNP: $p=0.027$; others: $p<0.001$ for all; Table 3). Levels of hs-cTnT, cfPWV and cAIx had no statistically independent association with rapid decline of renal function ( $p>0.05$ for all).

\section{Discussion}

Predictive abilities of cardiovascular biomarkers to rapid decline of renal function have been mainly discussed in clinical patients, and few studies have been performed in community-dwelling population without GFR below $60 \mathrm{ml} / \mathrm{min} / 1.73 \mathrm{~m}^{2}$ [6-8]. Moreover, most of conflicting evidences have been provided by cross-sectional and short-term studies, and it is essential to perform the long-term prospective study to analyze this problem [9]. Almost no long-term prospective study has evaluated this problem in China [10]. This prospective analysis had the following findings during the follow-up of 5 years in Chinese community-dwelling population without GFR below $60 \mathrm{ml} / \mathrm{min} / 1.73 \mathrm{~m}^{2}: 1$. homocysteine and NTproBNP rather than hs-cTnT had the independent
Table 3 Predictive abilities of cardiovascular biomarkers to rapid decline of renal function in Logistic regression analysis

\begin{tabular}{|c|c|c|c|}
\hline Characteristics & $\mathrm{HR}$ & $95 \mathrm{Cl}$ & $P$-value \\
\hline Age (year) & 1.057 & $1.032-1.084$ & $<0.001$ \\
\hline Men (\%) & 2.531 & $1.564-4.096$ & $<0.001$ \\
\hline BMI (kg/m2) & 1.021 & $0.962-1.083$ & 0.493 \\
\hline SBP $(\mathrm{mmHg})$ & 0.987 & $0.971-1.003$ & 0.100 \\
\hline $\mathrm{DBP}(\mathrm{mmHg})$ & 1.019 & $0.994-1.045$ & 0.132 \\
\hline CAD (\%) & 0.681 & $0.365-1.269$ & 0.227 \\
\hline Hypertension (\%) & 1.740 & $1.059-2.857$ & 0.029 \\
\hline Diabetes (\%) & 0.743 & $0.436-1.266$ & 0.275 \\
\hline $\operatorname{cfPWW}(\mathrm{m} / \mathrm{s})$ & 0.985 & $0.905-1.072$ & 0.726 \\
\hline cAlx (\%) & 0.994 & $0.974-1.015$ & 0.561 \\
\hline TG (mmol/L) & 0.900 & $0.744-1.089$ & 0.280 \\
\hline $\mathrm{HDL-c}(\mathrm{mmol} / \mathrm{L})$ & 0.622 & $0.330-1.171$ & 0.141 \\
\hline LDL-c (mmol/L) & 0.919 & $0.693-1.219$ & 0.558 \\
\hline FBG (mmol/L) & 1.121 & $0.935-1.343$ & 0.217 \\
\hline PBG (mmol/L) & 1.061 & $0.976-1.153$ & 0.162 \\
\hline Homocysteine $(\mu \mathrm{mol} / \mathrm{L})$ & 1.048 & $1.024-1.072$ & $<0.001$ \\
\hline NT-proBNP (pg/ml) & 1.001 & $1.000-1.003$ & 0.027 \\
\hline Hs-cTnT (pg/ml) & 1.011 & $0.993-1.030$ & 0.220 \\
\hline Baseline GFR (mL/min/1.73 $\left.\mathrm{m}^{2}\right)$ & 1.117 & $1.098-1.136$ & $<0.001$ \\
\hline
\end{tabular}

Abbreviations: BMl: body mass index; cAlx: central augmentation index; CAD: coronary artery disease; cfPWV: carotid-femoral pulse wave velocity; Cl: confidence interval; DBP: diastolic blood pressure; FBG: fasting blood glucose; GFR: glomerular filtration rate; HDL-c: high-density lipoprotein cholesterol; hsCTnT: high-sensitivity cardiac troponin T; LDL-c: low-density lipoprotein cholesterol; NT-proBNP: N-terminal pro B-type natriuretic peptide; PBG: postprandial blood glucose; HR: hazard ratio; SBP: systolic blood pressure; TG: triglyceride

abilities to predict the rapid decline of renal function, with their higher levels indicating more rapid renal function decline rate; 2 . baseline GFR was an independent factor predicting the rapid decline of renal function; 3 . elderly and females had a more rapid decline of renal function compared with others; 4. role of hypertension in rapid decline of renal function could not be ignored; 5. arterial stiffness and compliance had no independent effect on rapid decline of renal function.

Cross-sectional researches have realized that homocysteine levels were negatively related to GFR in black and white adults [14]. However, an increase in homocysteine levels was not an independent risk factor for renal disease in a study with the follow-up of 2.2 years [15]. During the follow-up of 5 years, this prospective analysis demonstrated the independently predictive ability of homocysteine to not only renal function decline rate, but also rapid decline of renal function, strongly supporting the adverse effect of homocysteine on renal function. Homocysteine might play an etiologic role in renal function decline through injuring the renal blood vessels. As a pro-oxidant, homocysteine could diminish 
the nitric oxide-mediated vasodilation, promote the thrombosis and impede the fibrinolysis [16-19]. Elevated homocysteine levels could be a target of future intervention studies to slow the rapid decline of renal function, and folic acid might be a choice in clinical therapy of renal injury.

Professor Seki N has proposed that natriuretic peptide was an independent risk factor for renal function decline rate [20]. Professor Spanaus KS has reported that elevated NT-proBNP levels indicated an increased risk for accelerated progression of renal disease [21]. This prospective analysis, directing at Chinese communitydwelling populationn without GFR below $60 \mathrm{ml} / \mathrm{min} /$ $1.73 \mathrm{~m}^{2}$, identified the NT-proBNP as an independent risk factor for rapid decline of renal function. Endogenous NT-proBNP at physiological levels affects the glomerular filtration and renal function [22]. Glomerular hyperfiltration induces the glomerular hypertension and stretches the mesangial cells. Stretched cells secrete the cytokines that stimulate the production of extracellular matrix proteins, accumulation of which promotes the progression of renal injury. Moreover, natriuretic peptide receptor antagonist or angiotensin receptor blockade and neutral endopeptidase inhibition (ARNI, LCZ696) might be useful to prevent the renal injury [23, 24]. Therefore, effective monitoring of NT-proBNP levels could slow the rapid decline of renal function.

Age and baseline GFR have been suggested to correlate with ESKD [25]. Based on Epidemiologia do Idoso (EPIDOSO) Study, age and baseline GFR were associated with progressive decline in renal function [26]. Professor Seki $\mathrm{N}$ has realized that baseline GFR had significantly positive association with renal function decline rate [27]. This prospective analysis discovered in Chinese communitydwelling population without GFR below $60 \mathrm{ml} / \mathrm{min} /$ $1.73 \mathrm{~m}^{2}$ that baseline GFR was significantly related to rapid decline of renal function, which was consistent with prior finding that glomerular hyperfiltration was a determinant of renal function decline [28, 29]. Accordingly, the correction of glomerular hyperfiltration might be valuable for slowing the rapid decline of renal function. Meanwhile, the finding from Cardiovascular Health Study has suggested that elevated BP contributed to renal function decline in elderly [30]. According to Tromso Study, high BP predicted a decline in GFR [31]. However, Leiden 85-Plus Study has found that low BP was related to renal function decline in elderly [32]. This prospective analysis demonstrated a potential effect of hypertension on rapid decline of renal function in Chinese community-dwelling population without GFR below $60 \mathrm{ml} / \mathrm{min} / 1.73 \mathrm{~m}^{2}$.

Professor Ford ML has suggested that arterial stiffness was related to renal function decline rate [33]. In 482 community-dwelling individuals free from ESRD, renal function decline was associated with increased arterial stiffness [34]. However, professor Kim CS has illustrated that arterial stiffness was not associated with rapid decline of renal function in participants without GFR $<30 \mathrm{~mL} / \mathrm{min} / 1.73 \mathrm{~m}^{2}$ [35]. In this prospective analysis, arterial stiffness and compliance had no statistically independent effect on rapid decline of renal function in Chinese community-dwelling population without GFR below $60 \mathrm{ml} / \mathrm{min} / 1.73 \mathrm{~m}^{2}$.

The findings of this prospective analysis had public health relevance. Rapid decline of renal function has a growing prevalence in China. Given that there are limited interventions available, public health initiatives are needed for slowing the rapid decline of renal function. This prospective analysis confirmed that elevated homocysteine and NT-proBNP levels contributed to rapid decline of renal function. Future studies are required to determine whether therapies changing the homocysteine and natriuretic peptide levels ultimately affect the rapid decline of renal function. Effects of folic acid, natriuretic peptide receptor antagonist, angiotensin receptor blockade and neutral endopeptidase inhibition (LCZ696) and other medications associated with homocysteine and NT-proBNP levels on renal function are necessary to be paid special attention in pharmaceutical research and clinical practice.

The current analysis had some limitations. Firstly, 487 participants $(30 \%)$ were excluded due to missing values for variables, and it was difficult to determine their all variable information. However, there were only 181 participants lost during the follow-up of 5 years. Secondly, MDRD equation rather than Chronic Kidney Disease Epidemiology Collaboration (CKD-EPI) equation was applied to evaluate renal function in the current analysis. However, MDRD equation is more commonly applied in epidemiological investigation compared with CKD-EPI equation. Moreover, MDRD equation but not CKD-EPI equation has Chinese modified version (CMDRD). CMDRD equation is more suitable for Chinese community-dwelling population and has superior accuracy than CKD-EPI equation.

\section{Conclusions}

This prospective analysis demonstrated that homocysteine and NT-proBNP rather than hs-cTnT had independently predictive abilities to rapid decline of renal function in Chinese community-dwelling population without GFR below $60 \mathrm{ml} / \mathrm{min} / 1.73 \mathrm{~m}^{2}$. Moreover. baseline GFR was an independent factor predicting the rapid decline of renal function. Meanwhile, arterial stiffness and compliance had no independent effect on rapid decline of renal function. This prospective analysis has a significant implication for public health, and further studies are warranted to establish the benefit of interventions changing the homocysteine and NT-proBNP levels on slowing the rapid decline of renal function. 


\section{Abbreviations}

BMl: body mass index; cAlx: central augmentation index; cfPWV: carotid femoral pulse wave velocity; DBP: diastolic blood pressure; FBG: fasting blood glucose; GFR: glomerular filtration rate; HDL-c: high-density lipoprotein cholesterol; hs-cTnT: high-sensitivity cardiac troponin T; LDL-c: low-density lipoprotein cholesterol; NT-proBNP: N-terminal pro B-type natriuretic peptide; PBG: postprandial blood glucose; SBP: systolic blood pressure; TG: triglyceride

\section{Acknowledgments \\ Not applicable.}

\section{Funding}

This work was supported by grants from National Key Basic Research Project (2012CB517503 and 2013CB530804), Health Special Scientific Research Project of Chinese People's Liberation Army (12BJZ34 and 14BJZ12), and Sanya Medical and Health Science and Technology Innovation Project (2016YW21). The funding bodies played no role in study design, data acquisition, analysis and interpretation or manuscript preparation and submission.

\section{Availability of data and materials}

In attempt to preserve the privacy of patients, clinical data of patients will not be shared; data can be available from authors upon request.

\section{Authors' contributions}

FS, LC, LLM, YP: contributed to the design of study, performed the data collection and statistical analyses, and drafted the paper. All authors have read and approved the final version of this manuscript.

\section{Ethics approval and consent to participate}

The study was approved by Ethics Committee of Chinese People's Liberation Army General Hospital, China. Written consent was obtained from all participants.

\section{Consent for publication}

Not applicable.

\section{Competing interests}

The authors declare that they have no competing interests.

\section{Publisher's Note}

Springer Nature remains neutral with regard to jurisdictional claims in published maps and institutional affiliations.

\section{Author details}

'Department of Geriatric Cardiology, Chinese People's Liberation Army General Hospital, Beijing, China. ${ }^{2}$ Department of Cardiology and Hainan Branch, Chinese People's Liberation Army General Hospital, Beijing, China. ${ }^{3}$ Department of Nephrology and Hainan Branch, Chinese People's Liberation Army General Hospital, Beijing, China.

Received: 29 January 2017 Accepted: 19 October 2017

Published online: 09 November 2017

\section{References}

1. Rein P1, Saely $\mathrm{CH}$, Muendlein A, et al. Serial decline of renal function as a novel biomarker for the progression of atherothrombotic disease. Atherosclerosis. 2010;211:348-52.

2. Oh J, Wunsch R, Turzer M, et al. Advanced coronary and carotid arteriopathy in young adults with childhood-onset chronic renal failure. Circulation. 2002;106:100-5

3. Henry RM, Kostense PJ, Bos G, et al. Mild renal insufficiency is associated with increased cardiovascular mortality: the Hoorn study. Renal Int. 2002;62:1402-7.

4. Bostom AG, Kronenberg F, Jacques PF, et al. Proteinuria and plasma total homocysteine levels in chronic renal disease patients with a normal range serum creatinine: critical impact of true glomerular filtration rate. Atherosclerosis. 2001:159:219-23.

5. Ducloux D, Motte G, Challier B, et al. Serum total homocysteine and cardiovascular disease occurrence in chronic, stable renal transplant recipients: a prospective study. J Am Soc Nephrol. 2000;11:134-7.

6. Brattstrom L, Wilcken DE. Homocysteine and cardiovascular disease: cause or effect? Am J Clin Nutr. 2000;72:315-23.
7. Ueland PM, Refsum H, Beresford SA, et al. The controversy over homocysteine and cardiovascular risk. Am J Clin Nutr. 2000;72:324-32

8. Hiramoto JS, Katz R, Peralta CA, et al. Inflammation and coagulation markers and renal function decline: the multi-ethnic study of atherosclerosis (MESA) Am J renal Dis. 2012;60:225-32.

9. Francis $M E$, Eggers PW, Hostetter TH, et al. Association between serum homocysteine and markers of impaired renal function in adults in the United States. Renal Int. 2004;66:303-12.

10. Peralta CA, Katz R, DeBoer I, et al. Racial and ethnic differences in renal function decline among persons without chronic renal disease. J Am Soc Nephrol. 2011;22:1327-34.

11. Ma YC, Zuo L, Chen JH, et al. Modified glomerular filtration rate estimating equation for Chinese patients with chronic renal disease. J Am Soc Nephrol. 2006;17:2937-44.

12. Rifkin DE, Shlipak MG, Katz $R$, et al. Rapid renal function decline and mortality risk in older adults. Arch Intern Med. 2008;168:2212-8.

13. Eriksen $\mathrm{BO}$, Ingebretsen $\mathrm{OC}$. The progression of chronic renal disease: a 10year population based study of the effects of gender and age. Renal Int. 2006:69:375-82.

14. Ruan L, Chen W, Srinivasan SR, et al. Plasma homocysteine is adversely associated with glomerular filtration rate in asymptomatic black and white young adults: the Bogalusa heart study. Eur J Epidemiol. 2009;24:315-9.

15. Sarnak MJ, Wang SR, Beck GJ, et al. Homocysteine, cysteine, and B vitamins as predictors of renal disease progression. Am J renal Dis. 2002;40:932-9.

16. Davi G, Diminno G, Goppola A, et al. Oxidative stress and platelet activation in homozygous homocystinuria. Circulation. 2001;104:1124-8.

17. Stuhlinger MC, Tsao PS. Her JH, et al. Homocysteine impairs the nitric oxide synthase pathway: role of asymmetric dimethylarginine. Circulation. 2001; 104:2569-75.

18. Davi G, Diminno G, Coppola A, et al. Oxidative stress and platelet activation in homozygous homocystinuria. Circulation. 2001;104:1124-8.

19. Tofler GH, D'Agostino RB, Jacques PF, et al. Association between increased homocysteine levels and impaired fibrinolytic potential: potential mechanism for cardiovascular risk. Thromb Haemost. 2002;88:799-804.

20. Seki N1, Nishimura M, Matsumoto T, et al. Relationship between BNP level and renal function in diabetic nephropathy with microalbuminuria. J Diabetes Complicat. 2013;27:92-7.

21. Spanaus KS, Kronenberg F, Ritz E, et al. Mild-to-Moderate renal Disease Study Group. B-type natriuretic peptide concentrations predict the progression of nondiabetic chronic renal disease: the mild-to-moderate renal disease study. Clin Chem. 2007;53:1264-72

22. Jerums G, Premaratne E, Panagiotopoulos S, et al. The clinical significance of hyperfiltration in diabetes. Diabetologia. 2010;53:2093-104.

23. Sakamoto K, Kikkawa R, Haneda M, et al. Prevention of glomerular hyperfiltration in rats with streptozotocin-induced diabetes by an atrial natriuretic peptide receptor antagonist. Diabetologia. 1995;38: $536-42$.

24. Zhang PL, Mackenzie HS, Troy JL, et al. Effects of an atrial natriuretic peptide receptor antagonist on glomerular hyperfiltration in diabetic rats. J Am Soc Nephrol. 1994;4:1564-70

25. Hsu CY, Iribarren C, McCulloch CE, et al. Risk factors for end-stage renal disease: 25-year follow-up. Arch Intern Med. 2009;169:342-50.

26. Sesso R1, Prado F, Vicioso B, et al. Prospective study of progression of renal dysfunction in community-dwelling older adults. Nephrology (Carlton). 2008;13:99-103.

27. Seki N, Nishimura M, Matsumoto T, et al. Relationship between BNP level and renal function in diabetic nephropathy with microalbuminuria. J Diabetes Complicat. 2013;27:92-7.

28. Yokoyama H, Kanno S, Takahashi S, et al. Determinants of decline in glomerular filtration rate in nonproteinuric subjects with or without diabetes and hypertension. Clin J Am Soc Nephrol. 2009;4:1432-40.

29. Moriya T, Tsuchiya A, Okizaki S, et al. Glomerular hyperfiltration and increased glomerular filtration surface are associated with renal function decline in normo- and microalbuminuric type 2 diabetes. Renal International. 2011;81:486-93.

30. Rifkin DE, Katz R, Chonchol M, et al. Blood pressure components and decline in renal function in community-living older adults: the cardiovascular health study. Am J Hypertens. 2013:26:1037-44.

31. Kronborg J1, Solbu M, Njølstad I, et al. Predictors of change in estimated GFR: a population-based 7-year follow-up from the Tromso study. Nephrol Dial Transplant. 2008;23:2818-26 
32. van Bemmel T, Woittiez K, Blauw GJ, et al. Prospective study of the effect of blood pressure on renal function in old age: the Leiden 85-plus study. J Am Soc Nephrol. 2006;17:2561-6.

33. Ford ML, Tomlinson LA, Chapman TP, et al. Aortic stiffness is independently associated with rate of renal function decline in chronic renal disease stages 3 and 4. Hypertension. 2010;55:1110-5.

34. Elias MF, Davey A, Dore GA, et al. Deterioration in renal function is associated with increased arterial stiffness. Am J Hypertens. 2014;27:207-14.

35. Kim CS, Kim HY, Kang YU, et al. Association of pulse wave velocity and pulse pressure with decline in renal function. J Clin Hypertens (Greenwich). 2014;16:372-7.

Submit your next manuscript to BioMed Central and we will help you at every step:

- We accept pre-submission inquiries

- Our selector tool helps you to find the most relevant journal

- We provide round the clock customer support

- Convenient online submission

- Thorough peer review

- Inclusion in PubMed and all major indexing services

- Maximum visibility for your research

Submit your manuscript at www.biomedcentral.com/submit 